\title{
CDISC SDTM Device-In-Use Test Code Terminology
}

National Cancer Institute

\section{Source}

National Cancer Institute. CDISC SDTM Device-In-Use Test Code Terminology. NCI

Thesaurus. Code C106483.

Terminology associated with the device-in-use test code codelist of the Clinical Data

Interchange Standards Consortium (CDISC) Study Data Tabulation Model (SDT M). 